\title{
Petrogenesis Lava Bantal Nampurejo di Dusun Kalinampu dan Sekitarnya, Desa Jarum, Kecamatan Bayat, Kabupaten Klaten, Provinsi Jawa Tengah
}

\author{
Ishak Eliezer $^{1}$, Tri Winarno ${ }^{1 *}$, Rinal Khaidar $\mathrm{Ali}^{1}$ \\ ${ }^{1}$ Departemen Teknik Geologi Universitas Diponegoro, Semarang
}

\begin{abstract}
Abstrak
Lava bantal di Desa Jarum, Kecamatan Bayat, Kabupaten Klaten, Jawa Tengah masuk dalam Formasi Kebo-Butak. Lava bantal di Desa Jarum dikategorikan ke dalam Anggota Nampurejo. Lava bantal tersebut terbentuk pada Kala Oligosen. Masalah penelitian pada daerah ini ialah belum adanya penelitian mengenai lingkungan tektonik pembentuk batuan tersebut. Penelitian ini bertujuan untuk mengetahui karakteristik lava bantal, sehingga dapat diketahui genesa dari lava bantal tersebut. Penelitian ini dimulai dengan observasi lapangan berupa pemetaan geologi pada area seluas $2 \mathrm{~km} \times 2 \mathrm{~km}$, serta pengambilan sampel lava dan batuan di sekitar lava. Analisis petrografi bertujuan untuk mengetahui karakteristik dan komposisi mineral penyusun lava bantal. Analisis XRF (X-Ray Flourescence) bertujuan untuk mengetahui karakteristik geokimia magma yang membentuk lava. Lava yang ditemukan di lokasi penelitian bersifat setempat-setempat. Berdasarkan hasil analisis petrografi yang dilakukan sampel lava tersusun atas mineral plagioklas (andesin), augit, kalsit, dan mineral opaq. Berdasarkan hasil analisis petrografi, lava tersebut berjenis andesit. Hasil analisis geokimia menunjukkan bahwa magma penyusun lava masuk dalam seri kalk-alkali dengan lingkungan tektonik zona subduksi. Berdasarkan hasil penelitian disimpulkan bahwa lava merupakan produk erupsi gunungapi bawah laut yang terbentuk akibat adanya subduksi kerak Samudra Hindia terhadap kerak Benua Eurasia.
\end{abstract}

Kata kunci: Andesit; Bayat; Geokimia; Lava Bantal; Petrografi.

\begin{abstract}
Pillow lava in Jarum Village, Bayat District, Klaten Regency, Central Java belongs in Kebo-Butak Formation. Pillow lava in Jarum Village is categorized in Nampurejo Group. The pillow lava formed in Oligosen Epoch. The aims of this study is to determine pillow lavas characteristics to understand its genesis. The study aplly 3 methods which are field observation, thin section analysis, and XRF (X-Ray Fluorescence). Field observation and geological mapping covers $2 \mathrm{~km} \times 2 \mathrm{~km}$ area, and lavas and another rocks samples are collected around the lava sites. Thin section analysis aims to determine the characteristics and mineral composition of the pillow lava. The XRF analysis aims to determine the geochemical characteristic of magma that form lava. Lavas which found in the study area are spotted. Based on petrographic analysis, lavas are composed of plagioclase (andesine), augit, calcite, and opaq minerals. Based on petrographic analysis, the lava is categorized as andesite. Geochemical results showed the magma is catagorized as calc-alkali and formed in subduction zone. Based on the study concluded that lava is formed by a submarine volcanic eruption which formed by the subduction between Indian Oceanic crust and Eurasia Continent crust.
\end{abstract}

Key Words: Andesite; Bayat; Geochemistry; Pillow Lava; Petrography.

\section{PENDAHULUAN}

Daerah Bayat, Klaten merupakan daerah yang mempunyai keunikan variasi batuan yang tidak dijumpai di daerah lain. Salah satu formasi yang terdapat pada Kompleks Bayat yaitu Formasi Kebo-Butak. Pada formasi ini terdapat satuan yang tersusun oleh lava bantal yang disebut Lava Bantal Nampurejo. Lava Bantal Nampurejo, Formasi Kebo dan Formasi Butak merupakan satuan yang didominasi oleh batuan hasil kegiatan gunung api yang terbentuk pada Oligosen Awal hingga Miosen Awal. Formasi-formasi tersebut

*) Korespondensi: triwingeo@gmail.com 
tersusun atas lava bantal, batupasir hitam, batulanau, batuserpih, tufa, dan breksi (Surono, 2008). Penelitian terfokus pada Satuan Lava Bantal yang terdapat di Desa Jarum, Kecamatan Bayat, Kabupaten Klaten, Provinsi Jawa Tengah. Lokasi ini berada di sebelah utara Gunung Kidul, Provinsi Daerah Istimewa Yogyakarta

Lava Bantal Nampurejo memiliki struktur bantal dan memiliki komposisi basalt (Surono, 2008) dan menurut Mulyaningsih (2016) terjadi dua proses vulkanisme di lokasi penelitian yang mengakibatkan terendapkannya lava bantal dan endapan vulkanik feldspar. Penelitian ini bertujuan untuk mengetahui linkungan tektonik lava bantal. Diharapkan penelitian ini dapat melengkapi penelitian terdahulu pada Lava Bantal Nampurejo.

\section{METODOLOGI}

Metode penelitian yang dilakukan adalah observasi lapangan dan pemetaan geologi, pengambilan sampel batuan lava dan batuan daerah sekitarnya dan analisis laboratorium. Pemetaan geologi dilakukan untuk mengetahui karakteristik lava dan batuan di sekitar lava bantal, dan mengetahui persebaran lava di daerah penelitian. Sebanyak 2 sampel batuan dari lapangan dipakai untuk analisis petrografi dan analisis geokimia XRF (X-Ray Flourescence). Analisis sayatan tipis bertujuan untuk mengetahui komposisi mineralogi batuan dan analisis geokimia XRF bertujuan untuk mengetahui karakteristik geokimia batuan yang berguna untuk menentukan pengaruh tektonik yang menghasilkan lava di daerah penelitian.

\section{HASIL}

\section{Karakteristik Lava Bantal}

Lava bantal ditemukan di Dusun Kalinampu, Desa Jarum, dan Tegal Rejo. Lava bantal memiliki kenampakan megaskopis warna abu-abu cerah, namun berwarna abu-abu gelap dalam kondisi lapuk (Gambar 1). Mineral penyusun lava bersifat afanitik. Litologi lava bantal yang tersingkap pada daerah penelitian hanya terdapat pada lokasilokasi tertentu dengan diameter yang tidak terlalu besar. Pada tubuh lava terdapat adanya retakan radial mengikuti bentuk lingkaran struktur bantal yang terbentuk. Selain itu juga terlihat adanya rekahan yang ini telah diisi oleh mineral-mineral sekunder bersifat karbonatan berupa urat kalsit yang secara megaskopis memiliki warna putih dan berwarna putih kecokelatan pada kondisi lapuk. Selain mengisi retakan, mineral sekunder juga mengisi rongga-ronga yang terbentuk akibat pelepasan gas pada lava (amigdaloidal). Pada permukaan lava yang terdapat di Dusun Kalinampu terdapat rekahan yang menerus ke dalam mencapai rekahan radial disebut rekahan cangkang kura-kura yang terbentuk secara cepat dikarenakan lava panas langsung bertemu dengan air (Yamagishi, 1987).

Lava pada lokasi penelitian memiliki struktur bantal dan struktur breksi, dimana struktur bantal terbentuk akibat adanya kontak lava dengan air ketika lava keluar dari conduit gunung api. Kemudian, struktur breksi merupakan autobreksi yang terbentuk akibat adanya pendinginan pada permukaan lava sehingga membentuk blok-blok yang lebih keras. Struktur bantal memiliki ukuran bervariasi sekitar $40-100 \mathrm{~cm}$. Blok-blok breksi yang terdapat pada batuan bersifat koheren sehingga saling mengunci (McPhie dkk, 1993).

\section{Petrografi}

Pada satuan lava bantal diambil sampel sebanyak 2 buah dari 2 lokasi pengamatan yang berbeda. Titik pengambilan pertama terletak di Dusun Kalinampu yang merupakan singkapan lava bantal Nampurejo (kode ISHK-WB), diambil sebanyak satu sampel dan titik pengambilan kedua terletak di Dusun Tegalrejo (kode ISHK-PLB) diambil sebanyak satu buah sampel.

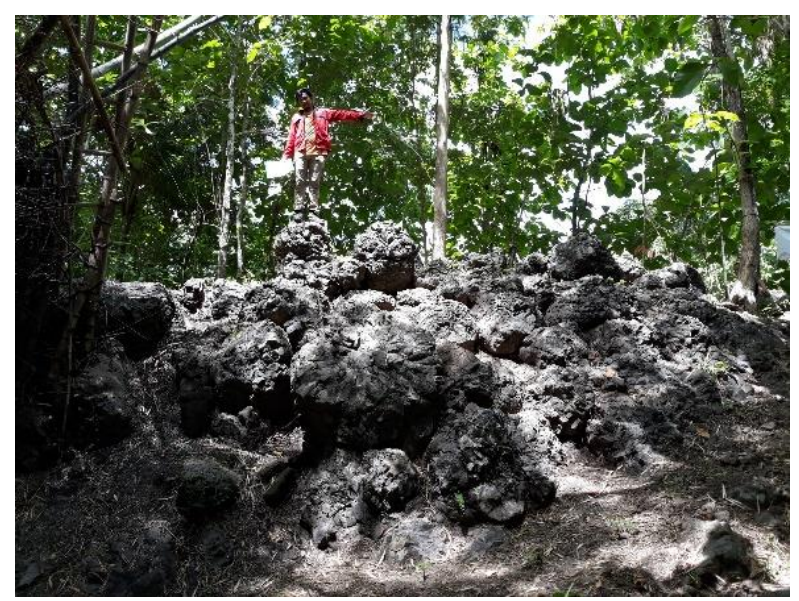

Gambar 1. Singkapan lava bantal Nampurejo di Dusun Kalinampu 


\section{Sayatan Lava Bantal}

Berdasarkan pengamatan petrografi, sampel lava bantal di Dusun Kalinampu (kode ISHK-WB) memiliki tingkat kristalinitas holokristalin, dengan bentuk kristal subhedral, ukuran kristal 0,2 mm $1 \mathrm{~mm}$, tingkat granularitas bersifat inequigranular (Gambar 2). Komposisi mineral berupa fenokris plagioklas dan klinopiroksen kemudian massadasar tersusun atas mineral plagioklas, sedikit piroksen dan mineral opak. Selain itu pada sayatan tipis ini juga terdapat mineral sekunder berupa kalsit. Plagioklas yang terdapat pada sampel lava ini dominan andesin, selain itu juga terdapat labradorit dan bytownite. Mineral plagioklas memiliki persentase kurang lebih 58\%.

Klinopiroksen pada sayatan ini umumnya merupakan augit dengan sudut gelapan berkisar antara $27^{\circ}-42^{\circ}$ dan memiliki persentase sekitar $12 \%$.. Kalsit pada sayatan ini membentuk urat dan memiliki persentase $7,66 \%$. Selain itu juga terdapat mineral afanit dengan persentase kurang lebih 9\%. Pada sayatan ini terdapat mineral plagioklas yang sudah berubah sebagian akibat adanya alterasi yang terjadi pada batuan. Dari hasil pengamatan didapat nama Andesit (Streckeisen, 1976). Pada pengamatan petrografi terhadap sampel lava bantal di Dususn Tegalrejo (ISHK-PLB), menunjukkan kenampakan tingkat kristalinitas holokristalin, dengan bentuk kristal anhedral - subhedral, ukuran kristal berkisar 0,2 $\mathrm{mm}-1 \mathrm{~mm}$, tingkat granularitas bersifat inequigranular (Gambar 3). Komposisi mineral penyusun fenokris berupa plagioklas, klinopiroksen, dan mineral opaq. Selain itu pada

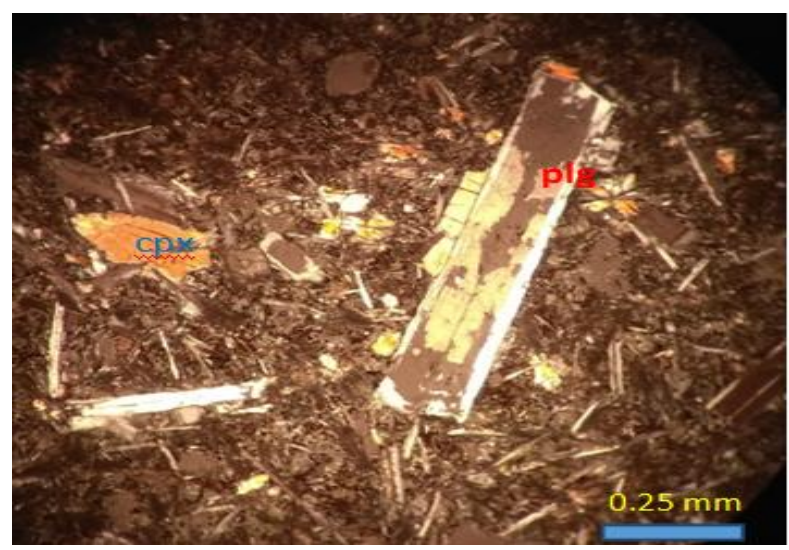

Gambar 2. Kenampakan petrografi sayatan lava bantal di Dusun Kalinampu (ISHK-WB). sayatan ini terdapat mineral sekunder berupa kalsit.

Plagioklas yang terdapat pada sampel lava ini berupa andesin, labradorit, dan bytownite. Pada sayatan ini juga ditemukan adanya pengaruh alterasi terhadap plagioklas. Plagioklas pada sayatan ini memiliki persentase kurang lebih $46 \%$.

Klinopiroksen pada sayatan ISHK-PLB memiliki warna interferensi oranye dengan bentuk kristal subhedral. Pada beberapa mineral piroksen terlihat kenampakan subopitik. Sudut gelapan yang terbentuk pada mineral ini memiliki rentang $42^{\circ}-49^{\circ}$. Beberapa klinopiroksen terlihat memiliki kembaran simpel. Persentase klinopiroksen kurang lebih $27 \%$.

Mineral opaq pada sayatan ini memiliki persentase $10 \%$ selain itu juga terdapat mineral kalsit $8,33 \%$ dan mineral afanit $10 \%$. Berdasarkan perhitungan persentase mineral didapatkan nama batuan andesit (Streckeisen, 1976).

\section{Data Geokimia}

Analisis geokimia dengan metode XRF dilakukan di Laboratorium PTBGN BATAN (Pusat Teknologi Bahan Galian Nuklir Badan Tenaga Nuklir Nasional). Analisis dilakukan pada batuan lava sebanyak 2 sampel, yaitu lava di Dusun Kalinampu (ISHK-WB) dan Tegalrejo (ISHKPLB) (Tabel 4.1).

Petrogenesis lava dan jenis batuan yang terbentuk dapat diketahui menggunakan beberapa

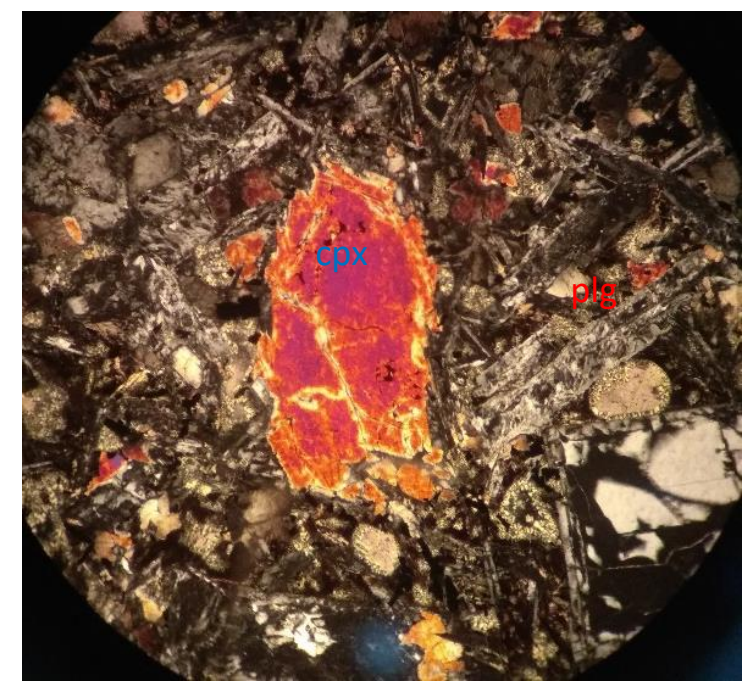

Gambar 3. Kenampakan petrografis sayatan lava di Dusun Tegalrejo ISHK-PLB 
Tabel 4.1. Hasil analisis kimia pada sampel lava

\begin{tabular}{lcccccccccc}
\hline $\begin{array}{l}\text { Kode } \\
\text { Sampel }\end{array}$ & $\mathbf{S i O}_{2}$ & $\mathbf{M g O}$ & $\mathrm{Al}_{2} \mathbf{O}_{3}$ & $\mathbf{N a 2 O}$ & $\mathbf{K}_{2} \mathbf{O}$ & $\mathbf{C a O}$ & $\mathbf{T i O}_{2}$ & $\mathbf{M n O}$ & $\mathbf{F e}_{2} \mathbf{O}_{3}$ & $\mathbf{P}_{2} \mathbf{O}_{\mathbf{5}}$ \\
\hline ISHK-WB & 53,29 & 4,656 & 18,54 & 3,93 & 1,05 & 9,65 & 1,369 & 0,106 & 9,825 & 0,287 \\
ISHK-PLB & 52,92 & 5,962 & 21,07 & 5,96 & 0,71 & 6,50 & 0,89 & 0,143 & 8,191 & 0,340 \\
\hline
\end{tabular}

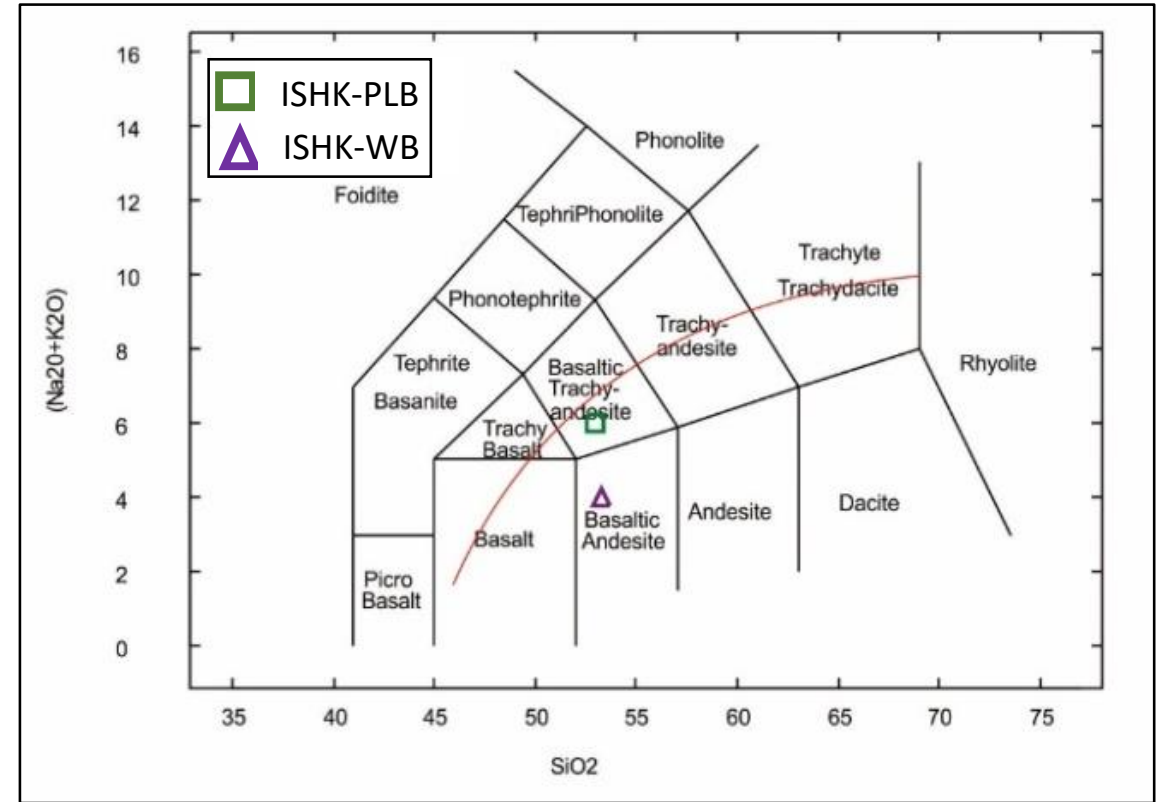

Gambar 4. Hasil plotting diagram TAS (Le Bas dkk, 1986).

diagram komposisi geokimia. Menurut Rollinson (1993), diagram TAS (Total Alkali versus Silika) merupakan diagram yang paling cocok digunakan pada batuan vulkanik. Diagram TAS membandingkan komposisi total alkali $\left(\mathrm{Na}_{2} \mathrm{O}\right.$ $\left.+\mathrm{K}_{2} \mathrm{O}\right)$ dengan jumlah silika $\left(\mathrm{SiO}_{2}\right)$ guna mengetahui jenis batuan.

Berdasarkan hasil analisis menggunakan diagram TAS seperti terlihat pada Gambar 4, batuan didaerah penelitian terbagi menjadi basaltik andesit dan basaltik trakit-andesit (Le Bas dkk., 1986). Dimana menurut Irvine dan Baragar (1971), kedua batuan tersebut masuk dalam seri batuan subalkali.

Salah satu diagram yang paling umum digunakan pada batuan beku ialah Diagram Harker. Pada diagram ini, $\mathrm{SiO}_{2}$ digunakan sebagai absis dikarenakan komposisinya yang yang meningkat seiring terjadinya evolusi magma (Harker, 1909 dalam Winter, 2014). Korelasi atau trend yang terjadi pada pasangan oksida dapat diakibatkan oleh terjadinya diferensiasi magma yang berkembang. Trend yang terbentuk pada diagram dibagi menjadi 2 yaitu trend positif dan negatif. Trend positif menunjukkan naiknya komposisi $\mathrm{SiO}_{2}$ seiring dengan naiknya komposisi oksida utama lainnya. Sedangkan trend negatif menunjukkan naiknya kandungan $\mathrm{SiO}_{2}$ seiring dengan penurunan komposisi oksida utama lainnya.

Pada Gambar 10 terlihat terjadinya bentuk trend naik, hal ini bukan dikarenakan terjadinya peningkatan komposisi Fe pada magma. Namun hal ini terjadi akibat adanya pembentukan mineral olivin dan piroksen didominasi oleh unsur $\mathrm{Mg}$ bukan $\mathrm{FeO}$.

Pada diagram $\mathrm{SiO}_{2}$ dengan $\mathrm{MgO}$ yang ada pada Gambar 5 terlihat terjadi penurunan. Menurut Winter (2014), penurunan $\mathrm{MgO}, \mathrm{FeO}$ dan $\mathrm{CaO}$ seiring peningkatan $\mathrm{SiO}_{2}$ terjadi akibat pembentukan mineral awal saat pendinginan magma. Kandungan $\mathrm{MgO}$ pada magma berhubungan dengan pembentukan mineral awal. $\mathrm{MgO}$ mengalami penurunan akibat fraksinasi 


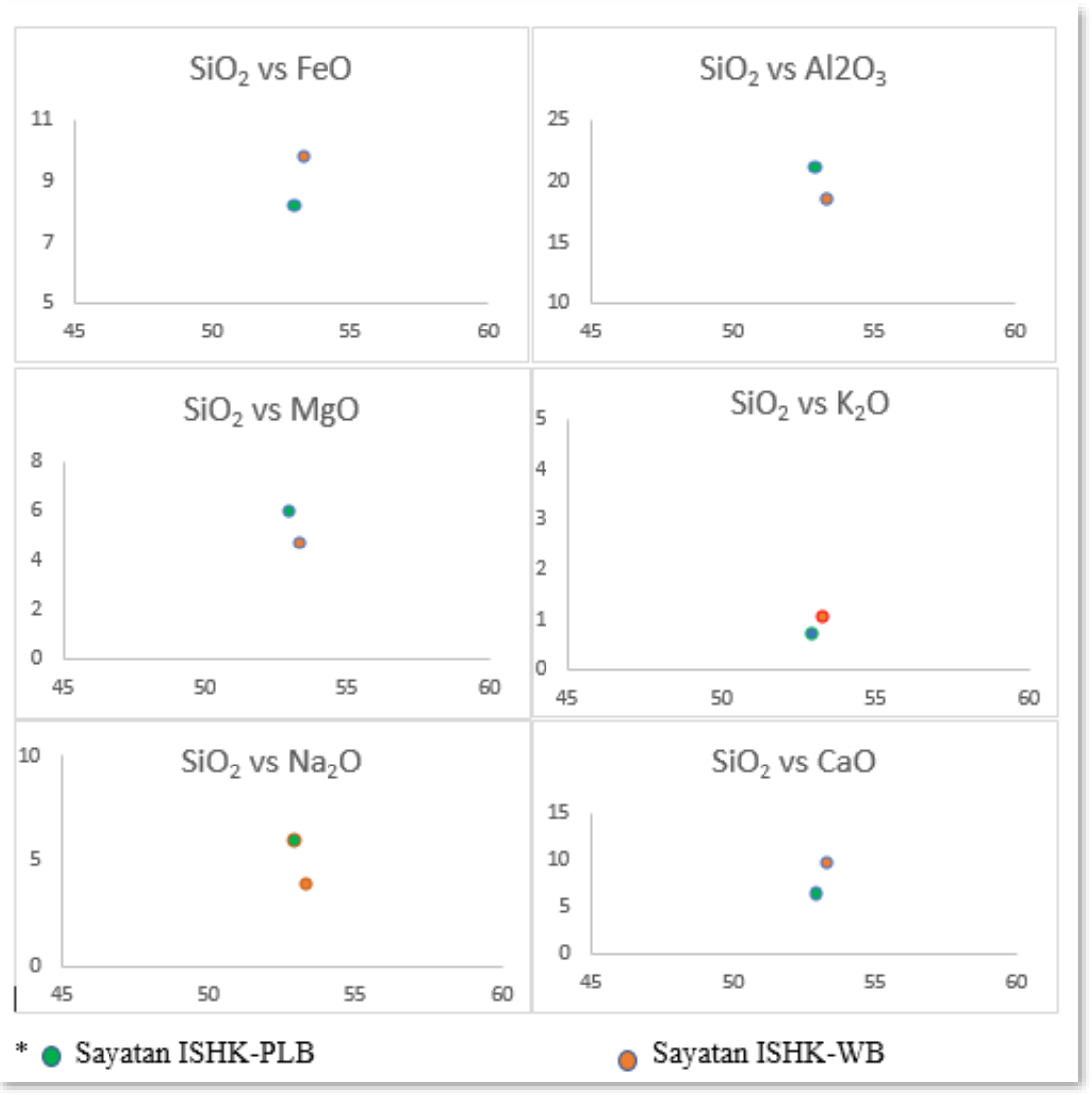

Gambar 5.Hasil plotting menggunakan Diagram Harker menunjukkan perubahan trend komposisi oksida utama terhadap SiO2 (Harker, 1909)

kristal yang terjadi saat pembentukan mineral olivin dan juga piroksen.

Berikutnya pada diagram $\mathrm{SiO}_{2}$ vs $\mathrm{CaO}$, kurang lebih sama dengan yang terjadi dengan trend $\mathrm{FeO}$. Trend naik yang terjadi pada $\mathrm{CaO}$ bukan diakibatkan oleh peningkatan unsur namun lebih kepada tidak terjadinya pembentukan mineral plagioklas Ca seperti anortit dan bytownite.

Selain itu untuk mengetahui afinitas magma pembentuk batuan antara kalk-alkali dan juga tholeitik dibuat pengeplotan pada diagram AFM. Diagram AFM mengambil 3 komposisi oksida utama yang terdapat pada batuan untuk menentukan afinitas magma pada batuan subalkali (toleitik atau kalk-alkali). Diagram ini membandingkan alkali $\left(\mathrm{Na}_{2} \mathrm{O}\right)$, oksida $\mathrm{Fe}\left(\mathrm{Fe}_{2} \mathrm{O}_{3}\right)$, dan $\mathrm{MgO}$. Berdasarkan hasil plotting pada diagram AFM didapatkan afinitas magma berupa Kalk-alkali (Irvine dan Baragar, 1971) (Gambar 6).

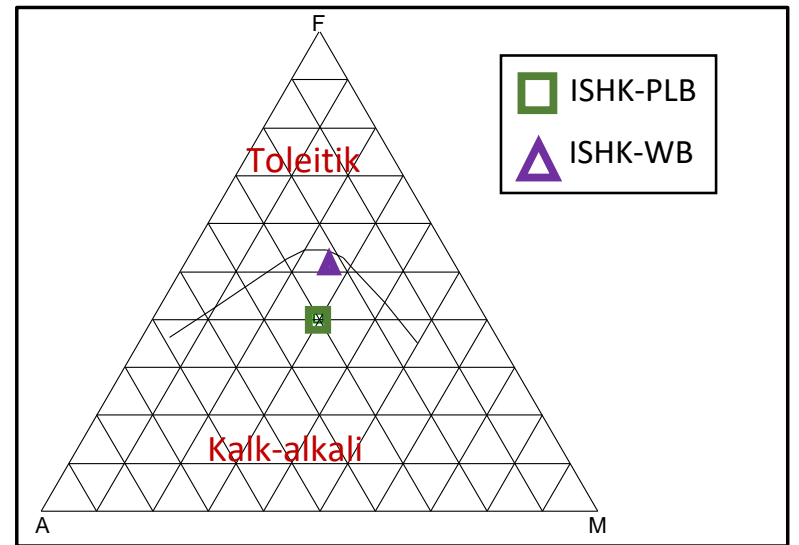

Gambar 6. Hasil plotting diagram AFM Irvine dan Baragar (1971).

Selanjutnya, untuk subdivisi kalk-alkali yang terdapat pada batuan, Peccerillo dan Taylor (1976) membuat diagram dimana pada diagram tersebut sub-alkali dibagi menjadi tiga yaitu low-K (Tholeiitic series), medium-K (Calc-Alkaline 
Series) dan high-K (High K Calc-Alkali Series). Pada diagram ini low- $K$ merupakan toleitik dan kedua yang lain merupakan kalk-alkali diagram ini membandingkan kadar unsur $\mathrm{K}_{2} \mathrm{O}$ dengan $\mathrm{SiO}_{2}$ (Gambar 7). Berdasarkan hasil plotting didapatkan bahwa kedua sampel batuan masuk ke dalam seri medium- $K$ (seri kalk-alkali).

Determinasi setting tectonic yang membentuk lava dapat diketahui dengan pendekatan geokimia oksida utama dengan bantuan diagram. Salah satu diagram yang dapat digunakan ialah Diagram $\mathrm{MgO}-\mathrm{FeO}-\mathrm{Al} 2 \mathrm{O} 3$ yang dibuat oleh Pearce dkk (1977) (Gambar 8). Diagram ini baik

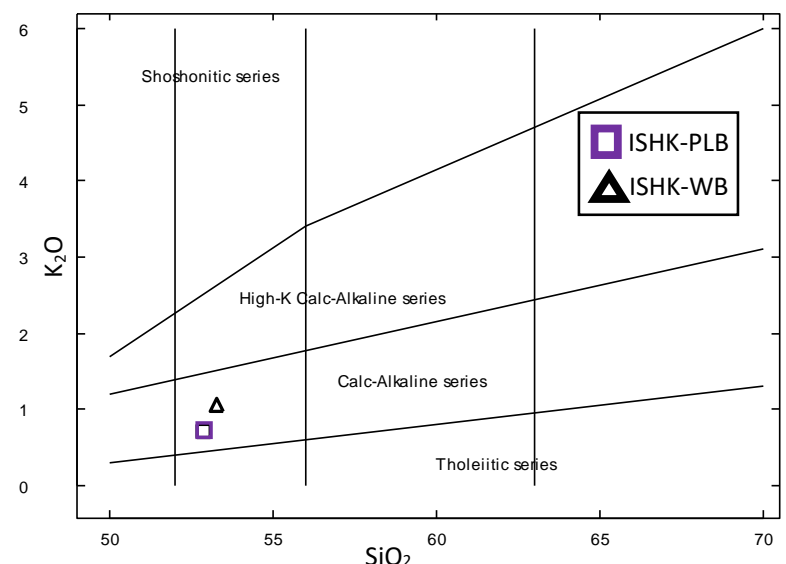

Gambar 7. Hasil plotting diagram perbandingan $\mathrm{SiO}_{2}$ dengan $\mathrm{K}_{2} \mathrm{O}$ (Paccerillo dan Taylor, 1976). digunakan untuk batuan dengan rentan kadar silika $51-56 \%$.

Selain itu juga dapat digunakan pada batuan vulkanik dengan afinitas magma subalkali. Selain itu juga dapat digunakan pada batuan vulkanik dengan afinitas magma subalkali. Berdasarkan hasil plotting pada diagram $\mathrm{MgO}-\mathrm{FeO}-\mathrm{Al} 2 \mathrm{O} 3$, diketahui bahwa setting tectonic terbentuknya lava berada pada island-arc and active continental margin.

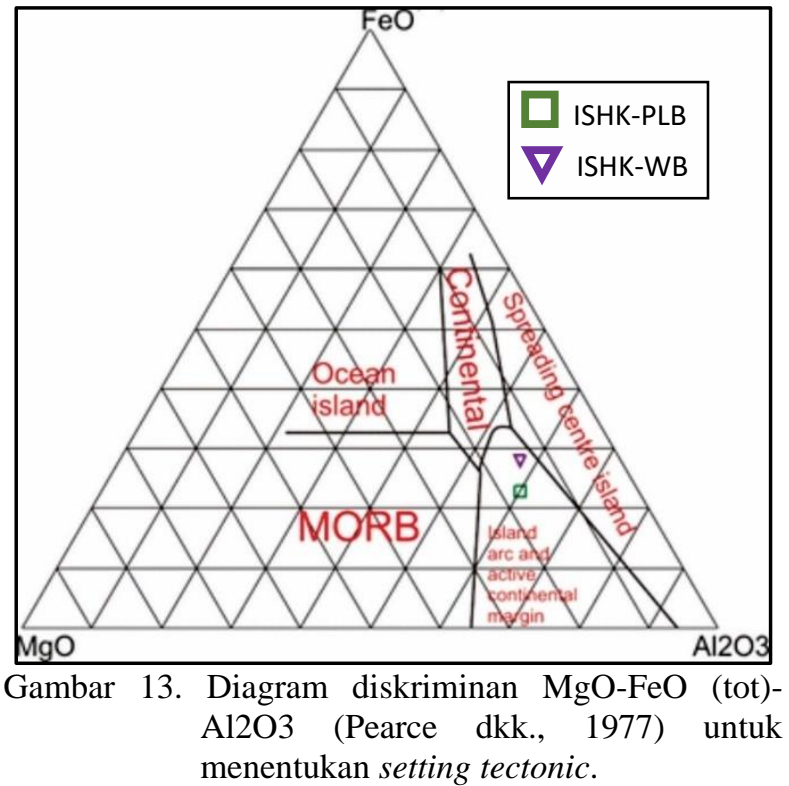

Tabel 2. Karakteristik magma yang terbentuk berdasarkan lingkungan tektonik tertentu (Wilson, 1989). Batas merah menunjukkan lingkungan tektonik yang dapat membentuk magma kal-alkali.

\begin{tabular}{|c|c|c|c|c|}
\hline \multirow[t]{2}{*}{ Tectonic Setting } & \multicolumn{2}{|c|}{ Plate margin } & \multicolumn{2}{|c|}{ Within plate } \\
\hline & $\begin{array}{l}\text { Convergent } \\
\text { (destructive) }\end{array}$ & $\begin{array}{l}\text { Divergent } \\
\text { (constructive) }\end{array}$ & Intra-Oceanic & $\begin{array}{l}\text { Intra- } \\
\text { continental }\end{array}$ \\
\hline $\begin{array}{l}\text { Volcanic } \\
\text { feature }\end{array}$ & $\begin{array}{l}\text { Island arcs, } \\
\text { active } \\
\text { continental } \\
\text { margin }\end{array}$ & $\begin{array}{l}\text { Mid-oceanic } \\
\text { ridges, back-arc } \\
\text { spreading } \\
\text { centers }\end{array}$ & Oceanic islands & $\begin{array}{l}\text { Continental rift } \\
\text { zones } \\
\text { Continental } \\
\text { flood basalt- } \\
\text { basalt provinces } \\
\text { Tholeiitic }\end{array}$ \\
\hline magma series & $\begin{array}{l}\text { Calc-alkaline } \\
\text { alkaline }\end{array}$ & - & alkaline & - \\
\hline $\mathrm{SiO}_{2}$ range & $\begin{array}{l}\text { Basalts and } \\
\text { differentiates }\end{array}$ & basalts & $\begin{array}{l}\text { Basalts and } \\
\text { differentiates }\end{array}$ & $\begin{array}{l}\text { Basalt and } \\
\text { differentiates }\end{array}$ \\
\hline
\end{tabular}


Tabel 2 menunjukkan karakteristik magma yang terbentuk berdasarkan lingkungan tektonik tertentu (Wilson, 1989). Batas merah menunjukkan lingkungan tektonik yang dapat membentuk magma kalk-alkali. Menurut Wilson (1989), magma umumnya muncul pada busur muda sedangkan magma kalk-alkali merupakan ciri dari busur lebih dewasa dan batas aktif lempeng benua. Kemudian Winter (2014), magma kalk-alkali pada dasarnya sangat berhubungan dengan proses subduksi.

Umumnya batuan volcanic arc memiliki karakteristik kimia yang lebih bervariasi dibanding dengan MORB (Mid Oceanic Rich Basalt).

\section{Petrogenesa Lava}

Berdasarkan hasil analisis diagram diskriminan seri magma AFM Irvine dan Baragar (1971) dan $\mathrm{SiO}_{2}$ versus $\mathrm{K}_{2} \mathrm{O}$ Pacerrillo dan Taylor (1976), Lava Bantal Nampurejo masuk dalam seri kalkalkali. Dilanjutkan dengan hasil analisis diagram diskriminan lingkungan tektonik $\mathrm{MgO}-\mathrm{FeO}_{(\text {tot })^{-}}$ $\mathrm{Al}_{2} \mathrm{O}_{3}$ (Pearce dkk., 1977), yang menunjukkan bahwa lingkungan tektonik berada pada lingkungan island arc dan active continental margin disimpulkan bahwa lokasi terbentuknya berada pada batas konvergen atau zona subduksi. Hal ini didukung oleh hasil diagram diskriminan $\mathrm{SiO}_{2}$ vs $\mathrm{K}_{2} \mathrm{O}$ yang menunjukkan bahwa seri magma yang terbentuk bersifat kalk-alkali. Menurut Wilson (1989) daerah subduksi berasosiasi dengan seri kalk-alkali. Zona subduksi merupakan hasil dari penujaman terhadap lempeng benua oleh lempeng samudera atau sebaliknya. Selain itu berdasarkan hasil pengamatan petrografi, yang mana didapati nama batuan berupa andesite menunjukkan bahwa magma pembentuknya bersifat intermediet. Dimana pada umumnya magma tipe ini terdapat pada gunung api yang terbentuk akibat pertemuan lempeng samudra dengan lempemg benua atau biasa disebut zona subduksi.

Menurut Wilson (1989), magma primer memiliki komposisi $\mathrm{Mg}>7 \%$, Ni (400-500 ppm), $\mathrm{Cr}$ (>1000 ppm), dan $\mathrm{SiO}_{2}$ tidak lebih dari $50 \%$. Sehingga, disimpulkan bahwa magma yang menyusun lava bukan magma primer sudah mengalami proses diferensiasi.

Pada Kala Eosen, pergerakan mikrokontinen Jawa Timur mengalami kemunduran pergerakan yang mengakibatkan terjadinya subduksi pada salah satu sisi mikrokontinen pada Eosen Akhir. Proses subduksi tersebut mengakibatkan terjadinya partial melting pada bagian kerak samudera dan kerak benua (Gambar 14). Proses partial melting terjadi dibantu oleh $\mathrm{H}_{2} \mathrm{O}$ yang dibawa oleh kerak samudera yang kemudian mengalir ke dasar kerak benua dan juga tekanan yang tinggi yang terbentuk diantara kedua kerak. Proses partial melting tersebut mengakibatkan terjadinya percampuran magma secara geokimia.

Kemudian ketika magma bergerak keatas, terjadi fraksinasi kristal mineral-mineral yang terbentuk pada suhu tinggi seperti olivin. Selain itu juga saat partial melting dan asimilasi dengan batuan samping terjadi pada saat magma bergerak keatas, terjadi peningkatan unsur $\mathrm{K}$. Peningkatan unsur $\mathrm{K}$ ini yang mengakibatkan magma yang membentuk lava bantal didaerah penelitian masuk ke dalam seri medium $K$ kalkalkali.

Fraksinasi kristal terus terjadi seiring pergerakan magma menuju permukaan. Ketika magma mendekati permukaan mulai terbentuk fenokris berukuran kasar yang ditemui pada sayatan ISHK-WB dan ISHK-PLB. Kemudian pada Oligosen, lava keluar dari gunung api yang terbentuk dibawah permukaan air laut (Gambar 15). Lava ini membawa fenokris yang terbentuk sebelum keluar kepermukaan. Lava yang langsung kontak dengan air laut, mengalami pendinginan secara cepat dan kemudian membentuk struktur bantal. Lava bantal yang menjari dengan batuan sedimen menunjukkan bahwa proses pembentukan lava bantal lebih dari satu kali.

Lava Bantal Nampurejo dimasukkan dalam Formasi Kebo-Butak (Surono dkk., 1992 dan Surono, 2008). Mengacu pada Prasetyadi (2007) dan Surono (2008), Formasi Kebo-Butak terbentuk pada Oligosen Akhir hingga Miosen Awal. Pada Oligosen Akhir terjadi subduksi Lempeng Indo-Australia terhadap mikrokontinen Jawa Timur (Prasetyadi, 2007). 


\section{KESIMPULAN}

Daerah penelitian tersusun atas 3 satuan batuan, diantaranya Satuan Lava Bantal, Satuan Batu Pasir, dan Satuan Aluvium. Lava pada lokasi penelitian memiliki struktur bantal dan struktur breksi autoklastik. Struktur bantal yang terdapat pada lava menunjukkan bahwa lava terbentuk akibat adanya kontak dengan air laut dan menunjukkan bahwa lava terbentuk dibawah permukaan air. Struktur breksi pada lava terbentuk akibat adanya pendinginan pada permukaan lava akibat kontak dengan air ketika lava mengalir menuruni lereng. Lava Bantal Nampurejo tersusun atas fenokris plagioklas dan klinopiroksen. Keterdapatan mineral sekunder berupa urat kalsit menunjukkan telah terjadi alterasi pada tubuh lava. Analisis geokimia oksida utama menunjukkan afinitas magma pada Lava Bantal Nampurejo masuk ke dalam seri Subalkali kalk-alkali dengan komposisi K sedang. Lava Bantal Nampurejo terbentuk pada lingkungan subduksi dimana magma yang yang membentuk lava bukan merupakan magma primer melainkan magma yang telah mengalami diferensiasi.

\section{UCAPAN TERIMA KASIH}

Penulis menyampaikan terima kasih kepada seluruh perangkat Desa Jarum yang telah memberi izin penelitian di daerahnya serta memfasilitasi akomodasi selama pengambilan data lapangan, serta Departemen Teknik Geologi yang mendukung penuh dalam proses penyusunan artikel ini.

\section{DAFTAR PUSTAKA}

Badan Koordinasi Survey dan Pemetaan Nasional/ 2014. Peta Administrasi Kabupaten Klaten Skala 1: 65.000. https://petatematikindo.wordpress.com/20 15/01/04/administrasi-kabupaten-klaten/ (Diakses pada Januari 2018)

Harker, A. 1909. The Natural History of Igneous Rocks. Cambridge University Press.

Irvine, T.N. dan Baragar. 1971. A Guide to the Chemical Classification of the Common Rocks. Can. J. Earth Science. 8, 523-48.
LeBas, M. J., LeMaitre, R. M., Streckeisen, A., Zanettin, B., 1986. A chemical classification of volcanic rocks based on the total alkali silica diagram. Journal of Petrology 27, hal.745-750.

McPhie, J., Doyle, M., dan Allen, R. 1993. Volcanic Textures: A guide to the interpretation of textures in volcanic rocks, University of Tasmania, Australia, $196 h$

Mulyaningsih, S. 2016. Volcanostratigraphic sequences of Kebo-Butak Formation at Bayat Geological Field Complex, Central Java Province and Yogyakarta Special Province, Indonesia. Indonesian Journal on Geoscience Vol. 3, hal. 77-94.

Pearce, T.H., B.E Gorman., dan T.C Birkett. 1977. The Relationship Between Major Element Chemistry and Tectonic Environment of Basic and Intermediet Volcanic Rocks. Earth Planet Science. 36, 121-32.

Peccerillo, A., dan S.R. Taylor 1976. Geochemistry of Eocene Calc-alkaline Volcanic Rocks from the Kastamonu Area, Northen Turkey. Contribution Mineral Petroleum. 58, 63-81.

Prasetyadi, C. 2007. Evolusi Tektonik Paleogen Jawa Bagian Timur. Disertasi, Program Doktor Teknik Geologi. Institut Teknologi Bandung.

Rahardjo, W. 2004. Geologi Daerah Perbukitan Jiwo, Bayat, Klaten. Yogyakarta: Jurusan Teknik Geologi FT UGM.

Rollinson, H.R. 1993. Using Geochemical Data: Evaluation, Presemtation, Interpretation. Pearson Education Limited. Edinburgh Gate. England.

Surono. 2008. Litostratigrafi dan Sedimentasi Formasi Kebo dan Formasi Butak di Pegunungan Baturagung, Jawa Tengah Bagian Selatan. Jurnal Geologi Indonesia, Vol.3 No. 4: 183-193. 
Surono., Toha, B., dan Sudarno, I. 1992. Peta Geologi Lembar Surakarta-Giritontro, Jawa, Skala 1:100.000. Pusat Penelitian dan Pengembangan Geologi, Bandung.

Wilson, M. 1989. Igneous Petrogenesis. Department of Earth Sciences, University of Leeds. Springer: Belanda.

Winter, J.D. 2014. Principles of Igneous and Metamorpfic Petrology Second Edition. Pearson New International Edition. Pearson Educational Limited. Amerika Serikat

Yamagishi, H. 1987. Studies of The Neogene Subaqueous Lavas and Hyaloclastites in Southwest Hokkaido.Report of The Geological Survey of Hokkaido No. 59. H.56-1. 